\title{
PAPILLARY FIBROELASTOMA MIMICKING VEGETATION OF THE MITRAL VALVE
}

\author{
SU YOUNG KIM, MD ${ }^{1}$, TAE-HO PARK, MD ${ }^{1}$, DONG-YEOL LEE, MD¹, DONG HYUN LEE, MD', \\ YOUNG-RAK CHO, MD ${ }^{1}$, MOO-HYUN KIM, MD' ${ }^{1}$, YOUNG-DAE KIM, MD ${ }^{1}$ AND SOOK HEE HONG, MD ${ }^{2}$ \\ 'DIVISION OF CARDIOLOGY, DEPARTMENTS OF INTERNAL MEDICINE, ${ }^{2}$ PATHOLOGY, DONG-A UNIVERSITY COLLEGE OF MEDICINE, \\ BUSAN, KOREA
}

Although cardiac papillary fibroelastoma is rare, it is the most common primary tumor of cardiac valves. The clinical presentation of these tumors varies from asymptomatic to embolic complications. We report an asymptomatic case of papillary fibroelastoma of mitral valve which was diagnosed by transthoracic echocardiography. The tumor was successfully resected by surgery.

KEY WORDS: Papillary fibroelastoma · Mitral valve · Transthoracic echocardiography.

\section{INTRODUCTION}

The papillary fibroelastoma (PFE) is a rare and benign primary cardiac tumor. However, it is the most common tumor occurring in cardiac valves. Since the introduction of echocardiography, the diagnosis of these tumors in living patients has been reported sporadically. We describe an interesting case of PFE mimicking vegetation of the mitral valve by transthoracic echocardiography (TTE).

\section{CASE}

A 51-year-old man had been admitted to a regional hospital for treatment of avascular necrosis of the femoral head where he received antibiotics for 2 weeks to treat a suspicious vegetation apparent on TTE. Because the size of the cardiac mass had not changed, the patient was referred to our hospital for further evaluation.

On physical examination, his blood pressure was $110 / 70$ $\mathrm{mmHg}$, pulse rate $65 / \mathrm{min}$, respiration rate was $21 /$ minute, and body temperature was $36.7^{\circ} \mathrm{C}$. Heart sounds were regular without cardiac murmurs. Both lungs expanded symmetrically, and breath sounds were clear. The laboratory findings were as follows: hemoglobin, $14.6 \mathrm{~g} / \mathrm{dL}$; total leukocyte count,

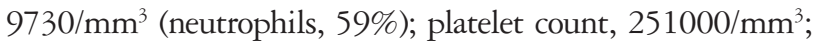
and erythrocyte sedimentation rate, $23 \mathrm{~mm} / \mathrm{hr}$. Results of urinalysis, blood chemistry, and electrolyte tests were within normal ranges. An electrocardiogram revealed normal sinus rhythm. Chest X-ray was normal, as was TTE except for a mass on the mitral valve. The mass was $1.0 \mathrm{~cm}$ in size, mobile, attached to anterior mitral leaflet, and round with a homogenously speckled surface (Fig. 1). There was no mitral regurgitation, stenosis or intracardiac shunt. Although the findings of TTE look like vegetation, the laboratory results did not show any evidence of infection and no signs or symptoms of infective endocarditis including Janeway lesion, Osler nodes, and conjunctival hemorrhage were detected in physical examination. Additionally no organisms were cultured in repeated microbiologic studies. Thus, the clinical and echocardiographic findings may represent cardiac tumor such as papillary fibroelastoma rather than vegetation or thrombus.

The cardiac mass was removed by surgery in order to reduce the risk of embolism for PFE as well as to rule out the infective endocarditis. Under standard cardiopulmonary bypass, the left atrium was opened vertically from the right side. On exploration, a $1.2 \times 1.0 \mathrm{~cm}$ pedunculated mass was found on the anterior mitral leaflet. On gross examination, the mass was soft, slippery, and had numerous filaments (Fig. 2). The mass was removed using a shave excision technique. However, there was significant mitral regurgitation after mass excision and following excision of the mitral leaflets and chordae, a mechanical valve was implanted. Histopathology confirmed that it was a benign PFE, comprising a central a vascular collagenous core of dense connective tissue surrounded by a peripher-

- Received: August 16, $2012 \cdot$ Revised: September 17, $2012 \cdot$ Accepted: November 21, 2012

- Address for Correspondence: Tae-Ho Park, Division of Cardiology, Department of Internal Medicine, Dong-A University College of Medicine,

26 Daesingongwon-ro, Seo-gu, Busan 602-715, Korea Tel: +82-51-240-2964, Fax: +82-51-242-1449, E-mail: thpark65@dau.ac.kr

- This is an Open Access article distributed under the terms of the Creative Commons Attribution Non-Commercial License (http://creativecommons.org/licenses/by-nc/3.0)

which permits unrestricted non-commercial use, distribution, and reproduction in any medium, provided the original work is properly cited. 

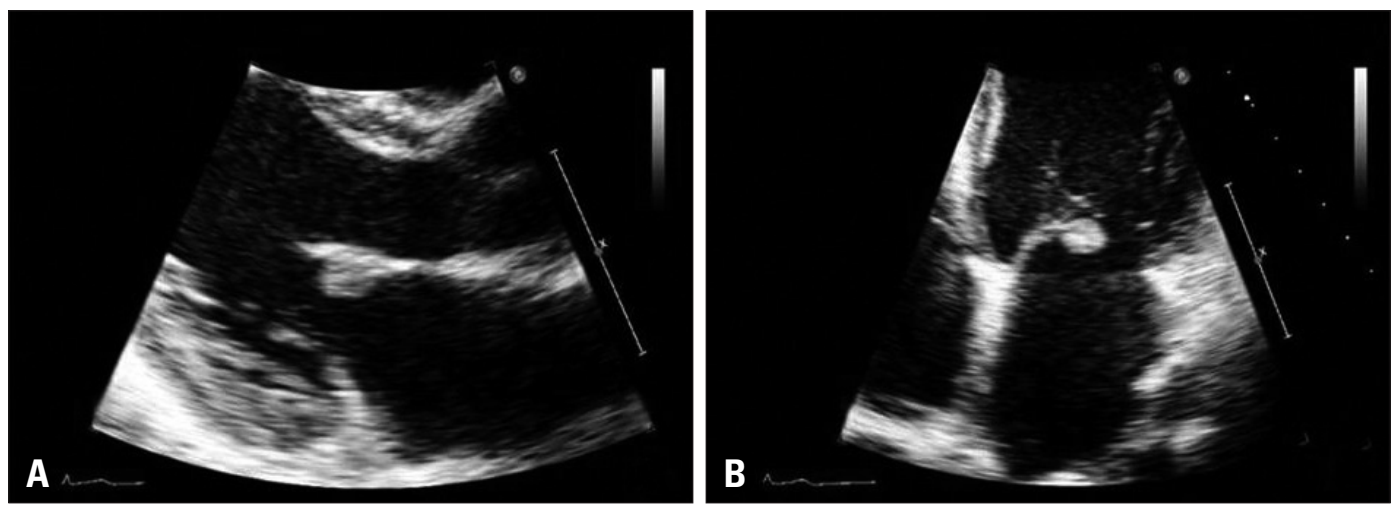

Fig. 1. Transthoracic echocardiography shows a mobile and spherical mass of $1.0 \mathrm{~cm}$ in size attached to anterior mitral leaflet. Parasternal long axis view (A) and an apical four-chamberview (B).

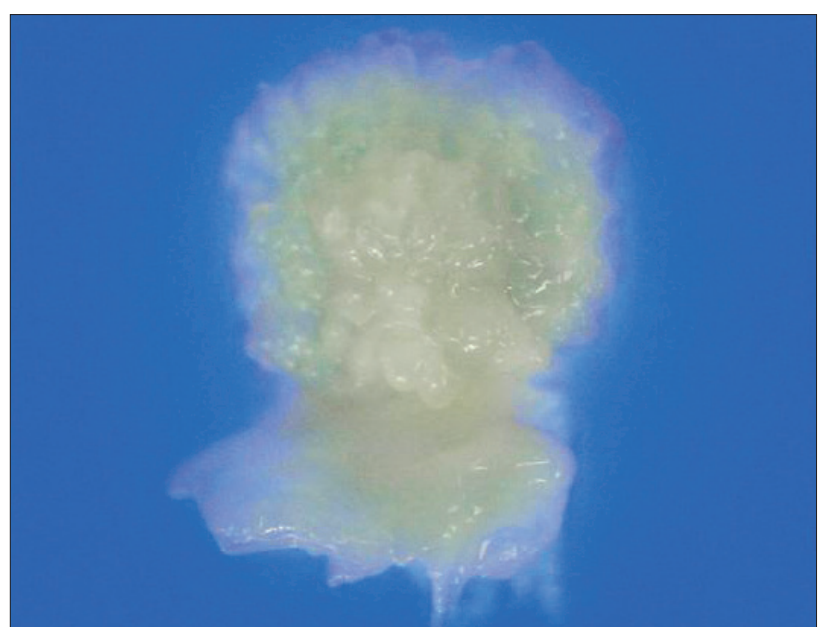

Fig. 2. Gross specimen of excised mass reveals a friable mass with frond-like surface.

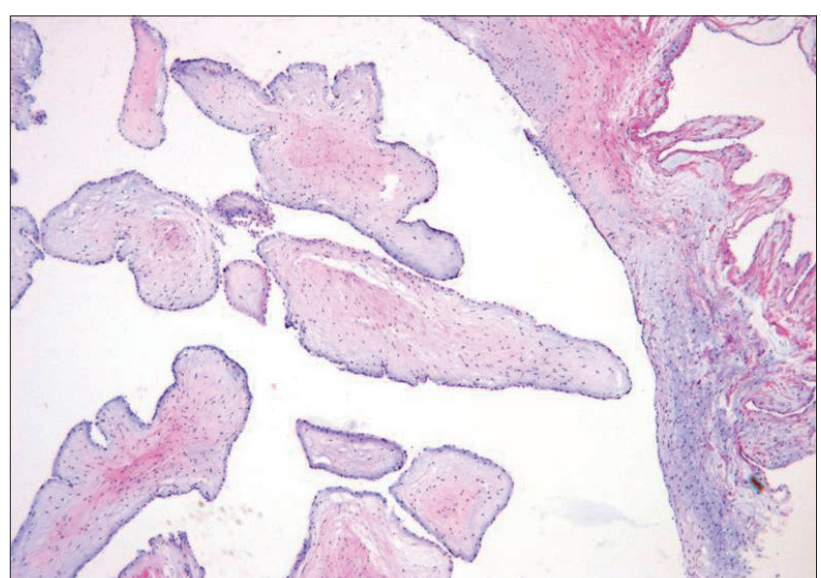

Fig. 3. Histological examination of the resected tumor showing papillary projection. The tumor surface is covered by a single layer of endocardial cells with an overlying thin layer of mucopolysaccharide matrix and an underlying acellular stroma composed of elastic fibers and collagen (Elastica van Gieson stain, $\times 40$ ).

al layer of loose connective tissue. The papillary surface was covered by a layer of endothelial cells and had fibrous stroma, including elastic fibers (Fig. 3). The postoperative course was uneventful and the patient was discharged in a satisfactory condition on the seventh day.

\section{DISCUSSION}

The prevalence of primary cardiac tumor ranges from $0.0017 \%$ to $0.28 \%$. $^{1)}$ The PFE is a rare benign cardiac tumor however it is the second most common cardiac tumor after myxoma and the most common tumor occurring in cardiac valves. ${ }^{2)}$ Although PFEs are benign, they can cause serious complications such as thromboembolism, myocardial ischemia, stroke and sudden death. ${ }^{\left.3)^{4}\right)}$ Gowda et al. ${ }^{5)}$ reported that systemic embolism was more frequently found in PFE of mitral valve than of aortic valve. However, most of cardiac PFE are found incidentally at the time of routine echocardiography or autopsy.

Surgical excision of PFE is recommended for symptomatic patients. For asymptomatic patients, however, the treatment course is less obvious. Some reports suggested that the fragile nature and frond-like papillary tissues of the tumor itself is prone to thromboembolism. Therefore, once diagnosed, urgent surgical management is indicated even in asymptomatic patients. ${ }^{6-8)}$ Other studies have suggested that careful observation is an acceptable option for asymptomatic patients, as long as the tumor remains small and nonmobile."

Considering the patient's age, tumor mobility and tumor size, we decided to remove the cardiac mass to prevent potential complications such as embolization. A simple shave excision is the most commonly used technique to surgically excise PFE." However, in this case, after mass excision, significant mitral regurgitation occurred, thus a mechanical valve was implanted. Although postoperative mitral prosthetic leakage was reported, ${ }^{10)}$ majority of patients with mechanical prosthesis were uneventful.

The differential diagnosis of PFE includes other cardiac tumors, thrombus, vegetation, and Lambl's excrescences. PFE has several characteristic findings which may help to differentiate it from thrombus or vegetation. Similar to vegetations, PFE is usually found on cardiac valves however PFE is often a solitary mass, usually of small size $(<1 \mathrm{~cm})$, usually at the midportion of valve leaflets, and with a frond-like characteristic 
surface. However, PFE may lack some of these findings whereas vegetations may represent many of these characteristics. For that reason, PFE can often be differentiated by clinical informations, blood cultures and laboratory tests. In this case, there was no evidence for infection or vascular, immunologic phenomenon of infective endocarditis.

To summarize, we report a mitral valve mass as PFE on TTE by analyzing the characteristics of mass. The diagnosis was confirmed by histopathological examination after surgical removal. Finally, careful echocardiographic analyses during evaluation of valvular masses are strongly recommended for differential diagnosis.

\section{REFERENCES}

1. Reynen K. Frequency of primary tumors of the heart. Am J Cardiol 1996;77:107.

2. Mariscalco G, Bruno VD, Borsani P, Dominici C, Sala A. Papillary fibroelastoma: insight to a primary cardiac valve tumor. J Card Surg 2010; 25:198-205.

3. Karaeren H, Ilgenli TF, Celik T, Deveci S, Kuralay E, Barçin C, Uzun M, Genç C, Demirtas E. Papillary fibroelastoma of the mitral valve with systemic embolization. Echocardiography 2000;17:165-7.

4. Liebeskind DS, Buljubasic N, Saver JL. Cardioembolic stroke due to papillary fibroelastoma. J Stroke Cerebrovasc Dis 2001;10:94-5.

5. Gowda RM, Khan IA, Nair CK, Mehta NJ, Vasavada BC, Sacchi TJ. Cardiac papillary fibroelastoma: a comprehensive analysis of 725 cases. Am Heart J 2003;146:404-10.

6. Grinda JM, Couetil JP, Chauvaud S, D'Attellis N, Berrebi A, Fabiani JN, Deloche A, Carpentier A. Cardiac valve papillary fibroelastoma: surgical excision for revealed or potential embolization. J Thorac Cardiovasc Surg 1999;117:106-10.

7. Boodhwani M, Veinot JP, Hendry PJ. Surgical approach to cardiac papillary fibroelastomas. Can J Cardiol 2007;23:301-2.

8. Gopaldas RR, Atluri PV, Blaustein AS, Bakaeen FG, Huh J, Chu D. Papillary fibroelastoma of the aortic valve: operative approaches upon incidental discovery. Tex Heart Inst J 2009;36:160-3.

9. Sun JP, Asher CR, Yang XS, Cheng GG, Scalia GM, Massed AG, Griffin BP, Ratliff NB, Stewart WJ, Thomas JD. Clinical and echocardiographic characteristics of papillary fibroelastomas: a retrospective and prospective study in 162 patients. Circulation 2001;103:2687-93.

10. Tanaka H, Narisawa T, Mori T, Masuda Y, Kishi D. Double primary left ventricular and aortic valve papillary fibroelastoma. Circ J 2004;68: 504-6. 